\title{
Characterization of Cohesive Cake Formation and Stickiness of Starches at Various Water Levels in the Presence of Palm oil and Palm Oil Fractions
}

\author{
Hasmadi Mamat ${ }^{\#}$, Mansoor Abd. Hamid ${ }^{\#} \&$ Sandra E. Hill ${ }^{*}$ \\ ${ }^{\#}$ Food Technology \& Bioprocess Program, School of Food Science \& Nutrition, University Malaysia Sabah, Malaysia \\ E-mail:idamsah@ums.edu.my; mah_chotey@ums.edu.my \\ * Food Sciences Division, School of Biosciences, University of Nottingham, Leicestershire, United Kingdom \\ E-mail: sandra.hill@nottingham.ac.uk
}

\begin{abstract}
A key feature of the biscuit manufacture is the combination of the raw ingredients. Different oils are likely to change the quality of dough. The factors important in agglomeration of starch materials are poorly understood and therefore work was carried out to try and establish the behaviour of oil and water on the material properties of starches. An understanding of particle-particle behaviour in the presence of oils and water is relevant to a food production process such as biscuit making, that requires preparation and mixing of these ingredients at ambient conditions. The way these powders pack and flow could have a significant impact on the final quality of the product. Powder flow analyser was used to measure the caking and cohesion properties for different type of starches. Besides the powder type as a variable, three levels of water and four types of oils at $5 \%$ (d.b) concentration were also tested. The presence of water with the powder plays an important role for the way the cereals powders pack and flow. Although tapped bulk densities did not vary much the water had a great impact on the powder caking strength and cohesion index. For samples without oil, the results showed that these parameters were increased significantly as the water level increased for all starches. Plasticization by addition of water to the food powder is believed to be the major factor contributing to the results obtained. Addition of oil to starches increased the caking and cohesion indices where liquid oils showed the greatest impact compared to solid oils.
\end{abstract}

Keywords — Caking index; cohesion index; stickiness; palm oil fractions

\section{INTRODUCTION}

Food powder property measurements such as flowabality and caking formation, are important because they reflect the powders' behaviour during storage, handling and processing. Powder flow is defined as the relative movement of the bulk of particles to neighbouring particles, or to the wall surface of container [16]. Powders or granular materials can be produced with a variety of different physical properties that influence their behaviour during preparation or processing. Particle properties that affect flowability include mean particle size, size distribution, particle shape, surface roughness and moisture content. Humidity, temperature and pressure also influence the flowability of granular solids and powders [9]. Amongst the major factors known to influence the flowabality of powders the effect of moisture content is most widely studied ([14], [19], [15], [8], [12]). Powders tend to absorb water which may form liquid bridges between powder particles and can lead to greater powder cohesion, reduced flowablity and increase powders' stickiness. Stickiness and cake formation in food powders have been recognized as one of major problem during storage, handling and processing. Starch powders are a mixture of an amorphous and crystalline form. If it is prone to stickiness and caking is must be due to the presence of the amorphous structures. Various techniques have been developed to measure the stickiness and caking formation in food powders. The most common and widely used method to measure powder flowabality is the Jenike shear cell apparatus. This method is commonly used for quantification of cohesion and adhesion of granular materials including food powders. In this method the powder is consolidated with the maximum applicable consolidation load. A detailed explanation was given by Reference [5] for this technique. Although this method provides useful information on the cohesive force between particles these methods are not suitable to characterize semi-solid food materials, they are commonly used for investigation of the flow behaviour of powders through chutes and hoppers. Most of the published data 
define flow of food powders without the presence of any other components.

Recently, a powder rheometer has been developed by Stable Micro Systems as another method for measuring flowabality of food powders. Reference [1] used this technique to study the effect of water and oil on cereal powder flow and packing behaviour for two different commercial starches and flours (wheat and maize). $\mathrm{He}$ found that there were significance differences between starches and flours of the same cereal. The caking and cohesion indices were both increased as water level increased for the two starches, but inconsistent results occurred for the cereals flours. The addition of oil increased the caking and the cohesion indices for both starches and wheat flour, where liquid oils showed more influence than the solid.

In this study, the cohesion and caking of potato, wheat (laboratory standard) and cassava starches was investigated with particular emphasis on the influence of presence of different types of oils and levels of moisture content using the rheometer powder flow analyzer by Stable Micro System.

\section{METHODOLOGY AND SAMPLES}

The measurements of caking strength and cohesion index were made and evaluated against data related to particle characterisation (particle size, tapped bulk density, oils utilisation of the particles etc). The samples used were potato, cassava and wheat samples with the presence of four palm oil fractions namely palm oil, palm olein, palm mid-fraction and palm stearine. Wheat, cassava and potato starch were obtained from National Starch and Chemical Ltd (Manchester, UK). Sigma wheat starch was obtained from Sigma (Sigma-Aldrich Chemie GmbH, Germany). Palm oil and its fractions were provided by Loders Croklaan (the Netherlands). The material's water content was adjusted to three levels; $12.5,18.5$ and $30.0 \%$ respectively, on material wet basis.

\section{A. Laser diffraction particle size analyzer}

The scattering of light is one of the most widely used techniques for measuring the size distribution of particles. The principle of the method is simple: a laser light source is used to illuminate particulates, usually contained within a suitable sample cell. The light scattered by the particles is then detected by silicon photo-detectors. The intensity of light on each detector measured as a function of angle is then subjected to mathematical analysis using a complex inversion matrix algorithm. The particle size was determined for this work using a laser diffraction particle size analyzer LS 13320 (Beckman Coulter, Inc., Fullerton, CA), equipped with an optical bench and a Universal Liquid Module to measure the size distribution of particles suspended in propanol-2. Analysis was conducted at a pump speed setting of $50 \%$. The result is a particle size distribution displayed as volume $\%$ in discrete size classes. All measurements were obtained in triplicate.

\section{B. Flow behaviour characterisation}

Caking strength and cohesion index were measured using powder rheometry (texture analyzer, TA-XT2 Plus, Stable Micro System, UK). The samples were packed in the container of the measuring vessel (borosilicate glass) and the apparent volume of the packed sample was fixed at $140 \mathrm{ml}$. A rotor was introduced into the packed powder sample using rotor blade with diameter and height of $10 \mathrm{~mm}$ and $48 \mathrm{~mm}$, respectively, with a rotation speed of $20 \mathrm{rpm}$ and a vertical velocity of $50 \mathrm{~mm} / \mathrm{s}$.

\section{Caking strength}

Caking test is to measure the potential of powder to form a cake and the force required to cut through the cake formed. The test is made up of 2 conditioning cycles to eliminate any user loading variation, and then 5 compaction cycles to form a powder bed. At the end of the $5^{\text {th }}$ cycle the blade then slices through the cake formed. The area under the curve (force required to cut through the cake bed) divided by the initial sample weight is the caking strength of the material.

\section{Cohesion Index}

The stickiness of a powder can be described in terms of cohesion - particle-particle stickiness. Cohesion is an internal property of a powder and is a measure of the forces holding the particles together. Particle cohesion is the important parameter for powder agglomeration. In this test, the blade slices the powder while moving downwards and lifts it while moving upwards. During these processes, the vertical load was measured by the load cell connected with the rotor and time dependent change was recorded. The cohesion index $(\mathrm{mm})$ is defined as the ratio "cohesion coefficient/sample weight". The cohesion coefficient ( $\mathrm{g} \mathrm{mm}$ ) is determined during the decompression phase at $50 \mathrm{~mm} \mathrm{~s}^{-1}$ speed, by integrating the (negative) areas under the forcedisplacement curve. A negative value denotes the powder weight subjected to the rotor blade during the lifting process. If powder sticks to the blade, the value of the negative load increases. Essentially the data obtained can be used to compare the samples being tested with previously data, to access if it is more cohesive or more free flowing.

\section{E. Tapped bulk density}

The tap bulk density is the bulk density of a powder that has been settled into closer packing by tapping, jolting, or vibrating the measuring vessel on a surface for several times, than existed in the poured state [5]. The tapped bulk density was measured according to [11] with slight modification. The powder was filled to a known volume in a cylinder and lightly tapped 20 times on the hard table surface. The volume was then read directly from the cylinder and used to calculate the bulk tap density according to the relationship; mass/volume.

\section{RESULTS AND DISCUSSION}

\section{A. Particle size distribution determination by laser diffraction particle size analyser}

The stickiness and caking behaviour of powders can be related to the physical forms and dimensions of the particulates. Particle size has been considered as one of the most important physical properties which affect the flowabality of powders. Reference [18] reported that powders with particles size larger than $200 \mu \mathrm{m}$ are free flowing, while fine powders are subject to cohesion and their 
flowabality is more difficult. Particle size distribution is important in determining the way powders will flow or pack, therefore the materials' (starches and flours) particle size distribution was measured. A result is shown in Figure 1. Particle size distributions are displayed as volume \% in discrete size classes. The results show that differences in granule size distribution occur for the different botanical sources of starch. Cassava and potato starches exhibited two distinct peaks with the peak maxima occurring at 43.7 and $653.0 \mu \mathrm{m}$. The second peak showed larger sizes than those reported in the literature and it was believe that some of the granules are agglomerate. Sigma wheat starch had a wider particle size distribution compared to potato and cassava starch, and showed one big peak at 20.7 and a small peak at $101.1 \mu \mathrm{m}$. It was reported that wheat starch has two types of granules, small B-type granules (average diameter $<10 \mu \mathrm{m}$ ) and large A-type granules (average diameter $>10 \mu \mathrm{m}$ ) [17]. In general potato starch has a larger average particle diameter than wheat and cassava starches. The granules size were potato $>$ wheat $>$ cassava with range of their granule size were $5-100 \mu \mathrm{m}, 1-45 \mu \mathrm{m}$ and 4-35 $\mu \mathrm{m}$ respectively.

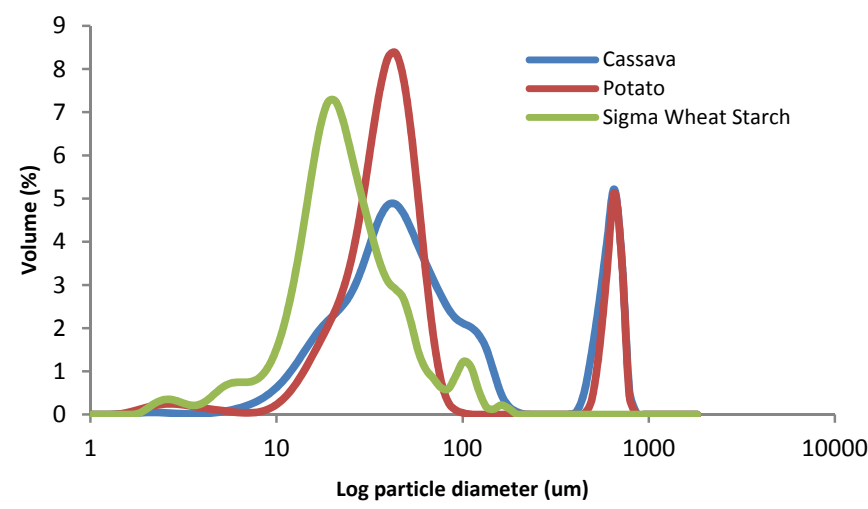

Fig. 1 Particle size distribution for potato, cassava and Sigma wheat starch

\section{B. Tapped bulk density}

Bulk density is defined as the mass of particles that occupies a unit volume of a container. Bulk density of granular solids and powders mostly depends on particle size, moisture, chemical composition, handling and processing operations. Tap density is the bulk density after a volume of powder has been tapped or vibrated under specific conditions. It can also be regarded as the compact density. Tapped bulk density is measured because the tapped value is more reproducibly than the bulk value. The minimum packed volume thus achieved depends on a number of factors including particle size distribution, true density, particle shape and cohesiveness due to surface forces that includes the influence of moisture and oil. Therefore, the tap density of a material can be used to predict both its flow properties and its compressibility. When water and oils were added to the cereals powders, it was expected that the volume occupied by the same material will vary depending on the material's properties.

\section{The effect of water and oils on starch powders density}

Figure 2 shows the tapped bulk density measured for the three starches at three selected water levels $(12.5,18.5$ and $30.0 \%$ ) and in the presence of $5 \%$ oils $(\mathrm{db})$. The values are the means of three replicates and one standard deviation is represented by the error bars for statistical comparison.

The results obtained show that potato starch packed with a greater density than cassava and wheat starches. It might be due to the size granule distributions as potato starch particles are bigger in comparison with those two starches. According to [7], the bulk density of a powder is dependent on the size and shape of the components. The finer particles might allow less air to escape, hence more volume. The effects of oil types were variable for the different type of starch and did not seem to have much impact on the densities.

\section{Microstructure of starches and flour under light microscopy}

Light microscopy was employed for characterizing native starches with respect to appearance, shape and size of the granules. The results showed that the morphology and microstructure of starch granules depended on their sources. The granules structures of potato, cassava and Sigma wheat starches show significant variations in size and shape (Figure 3 ). In the study, potato starch granules seemed to have oval and spherical shape whereas cassava starch was oval and truncated. Wheat starch granules had a round and oval shape. From the microscopy images, it can be seen that potato had bigger granules size compared to wheat and cassava. Variability of shape of food powders' particles may influence their bulk density property.
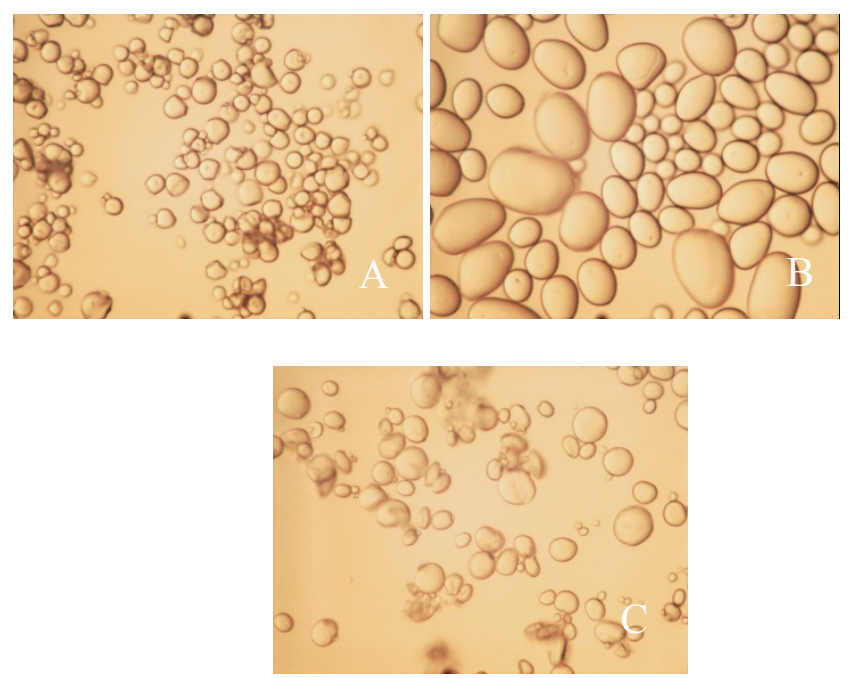

Fig. 2 Potato starch (A), cassava starch (B) and Sigma wheat starch (C) observed under light microscope (magnification 40X). Samples were dispersed in distilled water. $\mathrm{Bar}=100 \mu \mathrm{m}$. 


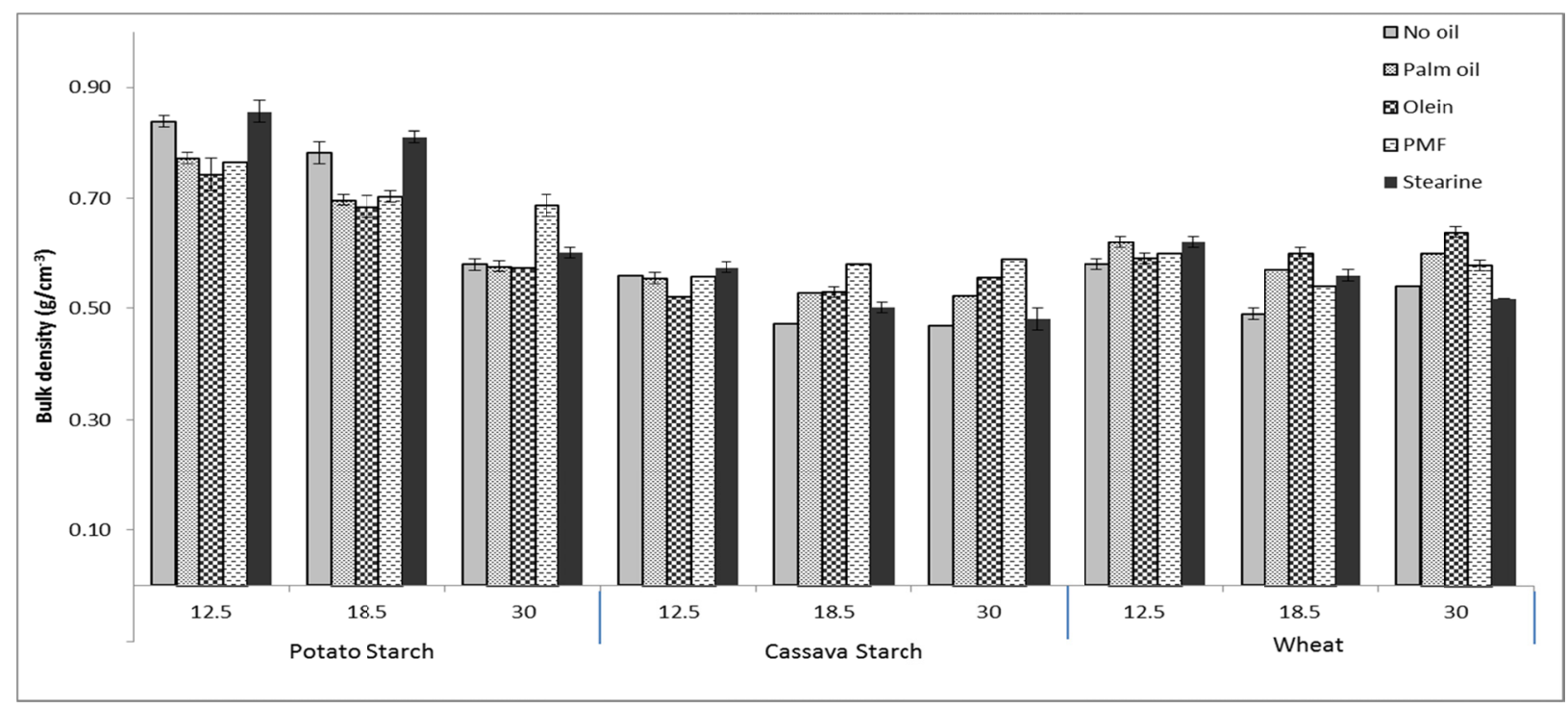

Fig. 3 Tapped bulk density of different starches at three water levels $(12.5,18.5$ and $30.0 \%)$ and $5 \%$ of oil. Error bars are \pm one standard deviation of three replicates.

\section{E. Effect of water and oil on starches caking and cohesion properties}

Food powders are complex due to their composition, their large distribution in particle size and the presence of solidliquid-gas phases in the particle. The presence of water in a powder can significantly affect its flowabality and caking properties. [1] observed a significant difference for caking and cohesion indices of wheat starch and maize starch as water level increased in the sample.

1) The effect of water on powders' caking strength and cohesion behaviour: Figure 4 show the results for the two parameters of cohesion index (CI) and caking strength index (CS) measured at three water levels. The figures demonstrated that water is playing an important role in the way cereal powders pack and flow. Caking and cohesion index values increased significantly as the moisture content of the all starches increased. In general, the greater the water content of a powder, the more cohesive the powder becomes and the more difficult it is to flow. Because food powders are moisture sensitive, the moisture content plays important role in cohesiveness. Water is known to act as an adhesive between particles by creating liquid bridges that increase the powder cohesiveness ([10], [6]). As the moisture content of the powder increases, the cohesion tends to increase ([14], [16]) and with the formation of liquid bridges between powder particles, there is greater powder cohesion and reduced flowability. Water absorbed onto the surface of a particle also tends to dissolve soluble components and form liquid bridges between particles that lead to cohesion and difficult flow. Upon dehydration, these liquid bridges are converted into strong solid bridges. The distance between the particles and hygroscopic properties of the particle components will influence the rate of caking. The higher the compactness of the particles and the finer the particles, the faster will be the caking [6].

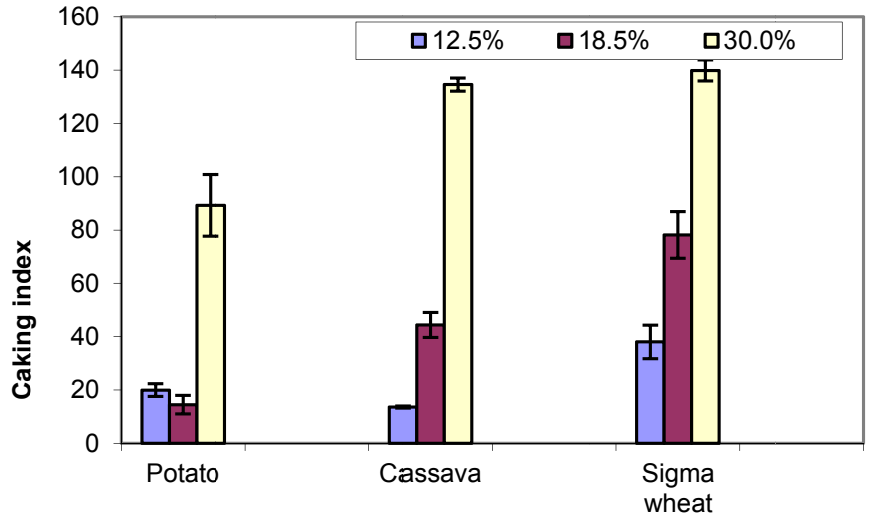

Type of starch

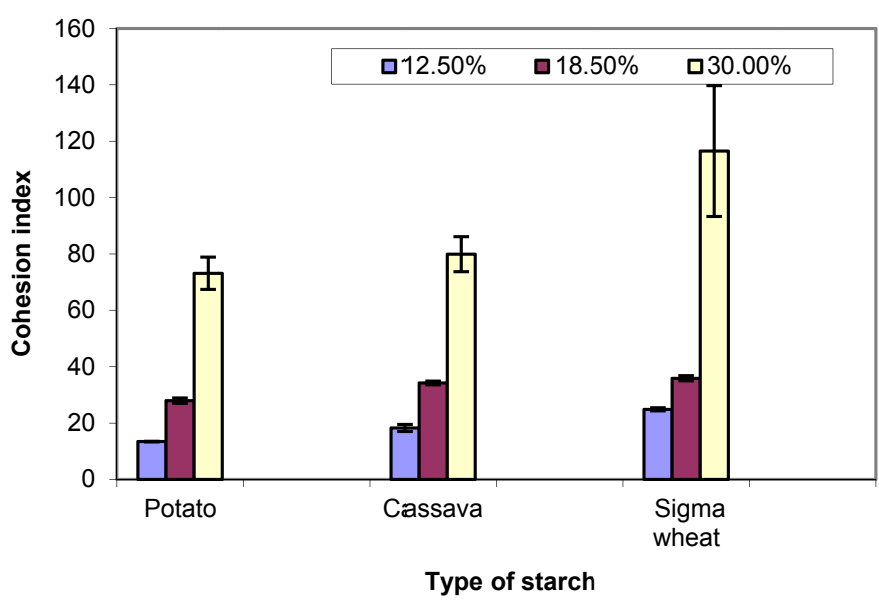

Fig. 4 Caking strength and cohesion index of various starches at different water levels, namely $12.5,18.5$ and $30.0 \%$, as showed in the figure. The values are the averages of three replications (mean \pm standard deviation) 
Wheat starch showed the highest caking and cohesion index for all samples at different levels of moisture content (12.5, 18.5 and $30.0 \%)$ compared to potato and cassava starch. Particle size distribution of these starches is believed to contribute to the results obtained. Reference [12] reported that an increase in flow difficulties and cohesiveness in conjunction with a reduction in particulate size for selected wheat powders. Wheat starch contained a higher amount of small granules particles (less than $10 \mu \mathrm{m}$ ), about $9.9 \%$ (of total volume) whereas potato and cassava only had 2.9 and $3.3 \%$, respectively. Wheat starch has two populations of granules, large A and small B. The smaller granules can increase the powder packing by filling the gaps between the larger ones. Fine particles size tends to increase cohesion and caking behavior because the particle surface area per unit mass increases, providing a great number of contact points, therefore more cohesive and less free flowing powders obtained ([18], [8]). This is an agreement with reference [13]. They reported that the finer the particle size and greater the range of particle sizes, the greater the cohesive strength, and lower the flow rate. Reduction in size increases the contact area between the particles, thereby increasing the cohesive forces.

Another possibility factor contributed to the results obtained is granules shape of the starches. Wheat starch had a round shape whilst potato and cassava had oval shape. Reference [2] concluded that differences of caking strength and cohesion index of wheat starch and maize starch contributed by the differences in the particle shape of these two starches. Powders with spherical shapes will pack more closely due to the lower frictional forces between the particles. The measured caking and cohesion would seem more sensitive to water content than the tap bulk density.

2) The effect of oil on powders caking strength and cohesion behaviour: Fats or shortening is one of the major ingredient components in the formulation of food products, particularly in the bakery. During the mixing process of biscuit for instance, all the ingredients were mixed together and produce a well-developed dough. In the previous section, it was shown that water content was a principal factor determining the powders' flow and packing properties. However, the presence of oil also altered the parameters to various degrees which might be related with the physical status of the fat used. According to [2], oil could affect changes in the behaviour of the starchy materials in two different ways. Firstly, the liquid oil could add to the moisture levels and provide an increase in the volume of the fluid phase in which the starchy material was suspended. Secondly, the oil could coat the starches and thus reduce the hydrophilic starch interaction with the aqueous phase. The concept of coated starches with oil before adding moisture is a well-established method to reduce $\mathrm{starch} / \mathrm{starch}$ interactions and hence clumping when water is added to starchy materials. Table 1 summarised the results of CI and CS obtained for the starches powders measured at three water levels and oil concentration of $5 \%$ of the total dry material weight.

When comparing the results obtained for starches with and without oil, addition of oil to the powder appeared to be one of the factors influencing the results. At $12.5 \%$ water level, CS and CI values for all the starches were increased when the starches were added with oil except CI values for starches with PMF. Similar trends observed for wheat and potato starches at $18.5 \%$ water level. No specific trends observed for CI and CS at $30 \%$ water level. At low water level $(\leq 18.5 \%)$, palm oil and palm olein showed higher CS and CI values compared to the other two oils. Presence of liquid oil (low melting point components) in the systems could produce liquid bridges between particles leading to higher stickiness index values. The powder flow is adversely affected by the presence of liquid bridges. Caking index value of stearine was lower for all the samples at different level of water. This is what was expected because high solid fat oil would obviously not become part of the fluid phase in the ambient conditions used in this study. Wheat starch with $12.5 \%$ water level showed higher caking index for all samples compared to other starches.

TABLE 1:

CAKING STRENGTH AND COHESION INDEX OF STARCHES WITH THREE WATER LEVELS AND $5 \%$ OF VARIOUS TYPE OF OIL

\begin{tabular}{|c|c|c|c|c|c|c|c|c|c|c|c|c|c|c|c|c|c|}
\hline \multirow{2}{*}{ Material } & \multirow{2}{*}{$\begin{array}{l}\text { MC } \\
(\%)\end{array}$} & \multicolumn{4}{|c|}{ Palm oil } & \multicolumn{4}{|c|}{ Palm olein } & \multicolumn{4}{|c|}{ Palm stearine } & \multicolumn{4}{|c|}{ Palm mid-fraction } \\
\hline & & $\mathrm{CS}$ & std & $\mathrm{CI}$ & std & $\mathrm{CS}$ & std & CI & std & $\mathrm{CS}$ & std & $\mathrm{CI}$ & std & $\mathrm{CS}$ & std & CI & std \\
\hline \multirow{3}{*}{ Potato } & 12.5 & 91.70 & 2.39 & 64.44 & 10.00 & 93.58 & 4.15 & 58.62 & 3.73 & 24.46 & 2.09 & 13.48 & 0.61 & 73.22 & 3.44 & 80.57 & 1.90 \\
\hline & 18.5 & 100.90 & 10.31 & 57.66 & 4.55 & 98.99 & 13.94 & 59.81 & 3.48 & 21.74 & 6.05 & 19.47 & 1.82 & 90.85 & 6.35 & 30.76 & 2.36 \\
\hline & 30.0 & 106.90 & 5.3 & 73.59 & 2.50 & 86.20 & 6.71 & 68.18 & 6.71 & 99.42 & 3.61 & 60.44 & 2.06 & 52.23 & 3.62 & 36.04 & 1.91 \\
\hline \multirow{3}{*}{ Cassava } & 12.5 & 139.80 & 13.71 & 32.73 & 2.03 & 182.30 & 3.20 & 53.39 & 1.69 & 32.89 & 0.74 & 13.65 & 0.16 & 124.90 & 1.53 & 25.55 & 1.80 \\
\hline & 18.5 & 128.6 & 16.59 & 31.08 & 0.44 & 134.50 & 0.87 & 49.02 & 0.86 & 46.43 & 8.15 & 33.61 & 1.31 & 172.80 & 13.80 & 21.36 & 0.28 \\
\hline & 30.0 & 125.5 & 5.21 & 74.89 & 3.77 & 115.10 & 12.47 & 75.90 & 11.76 & 138.30 & 6.36 & 77.33 & 6.50 & 89.80 & 5.69 & 62.84 & 0.29 \\
\hline \multirow{3}{*}{$\begin{array}{l}\text { Sigma } \\
\text { Wheat }\end{array}$} & 12.5 & 224.99 & 21.40 & 43.24 & 2.93 & 185.40 & 13.27 & 59.48 & 2.43 & 60.95 & 9.91 & 17.42 & 3.03 & 131.15 & 8.77 & 51.82 & 1.78 \\
\hline & 18.5 & 137.74 & 20.77 & 50.44 & 2.37 & 114.78 & 12.26 & 52.47 & 2.11 & 82.00 & 11.17 & 34.45 & 3.31 & 111.62 & 4.99 & 50.25 & 2.00 \\
\hline & 30.0 & 130.91 & 5.18 & 139.68 & 26.64 & 119.11 & 3.43 & 121.79 & 29.44 & 161.61 & 3.90 & 90.24 & 5.24 & 114.89 & 4.11 & 97.19 & 3.86 \\
\hline
\end{tabular}

The values are the averages of three replications (mean \pm standard deviation). $\mathrm{MC}=$ moisture content, $\mathrm{CS}=\mathrm{caking}$ strength index, $\mathrm{CI}-\mathrm{cohesion}$ index, std $=$ standard deviation 


\section{CONCLUSIONS}

The presence of water with the powder plays an important role for the way the cereals powders pack and flow. Although tap bulk densities did not vary much the water had a great impact on the powder caking strength and cohesion index. For samples without oil, the results showed that these parameters were increased significantly as the water level increased for all the starches. Plasticization by addition of water to the food powder is believed to be the major factor contributed the results obtained. Addition of oil has increased the caking and cohesion indices where liquid oils showed the greatest impact compared to solid oils.

\section{REFERENCES}

[1] M. Abu-Hardan, Biopolymers-oil interactions in expanded systems, University of Nottingham, Phd thesis, 2008.

[2] M. Abu-Hardan and S. E. Hill, Handling properties of cereal materials in the presence of moisture and oil, Powder Technology, 198:16-24, 2010.

[3] J. M. Aguilera, J. M. del Valle and M. Karel, Caking phenomena in amorphous food powders, Trends in Food Science \& Technology, 6: 149-155, 1995.

[4] G. V. Barbosa-Canovas and H. Yan, Powder characteristics of preprocessed cereal flours, In Characteritization of cereals and flours, Properties, analysis and application, Edt Kaletunc, G \& Breslauer, K. J. Marcel Dekker, New York, 2003.

[5] G. V. Barbosa-Canovas, E, Ortega-Rivas, P. E. Juliano and H. Yan, Food powders: Physical properties, processing, and functionality, Kluwer Academic Publisher, New York, 2005.

[6] B. R. Bhandari, Spray drying and powder properties, In: Food drying science and technology: Microbiology, Chemistry Application, H. Yan, M. Clary, M. M. Farid, O. O, Fasina, A. Noomhorm and J. Welti-Chanes, (Eds), DEStech Publication, Pennsylavania, USA, 2007.
[7] R. L. Brown and J. C. Richards, Principles of Powder Mechanics, Oxford, Pergamon Press, 1970

[8] J. J. Fitzpatrick, S. A. Barringer and T. Iqbal, Flow property measurement of food powders and sensivity of Jenike's hopper design methodology to the measured values, Journal of Food Engineering, 61, 399-405, 2004.

[9] V. Ganesan, K. A. Rosentrater and K. Muthukumarappan, Flowability and handling characteristics of bulk solids and powders - a review with implications for DDGS, Biosystems Engineering, $101,425-435,2008$.

[10] T. Groger, U. Tuzun and D. Heyes, Modelling and measuring of cohesion in wet granular materials, Powder Technology, 133:203215, 2003.

[11] V. Kumar, M. D. Reus-Medina and D. Yang, Preparation, characterization, and tabletting properties of a new cellulose-based pharmaceutical aid, International Journal of Pharmaceutics, 235(12):129-140, 2002

[12] V. Landillon, D. Cassan, M. Morel and B. Cuq, Flowability, cohesive, and granulation properties of wheat powders, Journal of Food Engineering, 86, 178-193, 2007.

[13] J. W. Marinelli and J. W. Carson, Solve solids flow problems in bins, hoppers, and feeders, Chemical Engineering Progress, pp. 22-28, 1992.

[14] R. Moreyra and M. Peleg, Effect of equilibrium water activity on the bulk properties of selected food powders, Journal of Food Science, 46, 1918-1922, 1981.

[15] N. Ozkan, N. Walisinghe and X. D. Chen, Characterization of stickiness and cake formation in whole and skim milk powders. Journal of Food Engineering, 55, 293-303, 2002.

[16] M. Peleg, C. H. Mannheim and N. Passy, Flow properties of some food powders, Journal of Food Science, 38, 959-964, 1973.

[17] A. B. Soulaka and W. R. Morrison, The amylose and lipid contents, dimensions and gelatinisation characteristics of some wheat starches and their A- and B- granule fractions, Journal of the Science of Food and Agriculture, 36:709-718, 1985.

[18] E. Teunou, J. J. Fitzpatrick and E. C. Synnott, Characterisation of food powder flowability, Journal of Food Engineering, 39, 31-37, 1999. 